\title{
ПРИМЕР УСПЕШНОГО ПРИМЕНЕНИЯ МЕТОДИКИ УЧЕТА ВЛИЯНИЯ НЕОДНОРОДНОСТЕЙ ВЧР В СЛОЖНЫХ УСЛОВИЯХ РАСПРОСТРАНЕНИЯ ЗОН ВЕЧНОЙ МЕРЗЛОТЫ В ЗАПАДНОЙ СИБИРИ
}

Гениита А.Н., Гатаулина Э.Р.

$(O A O «\lfloor\Gamma Э »)$

В настоящей работе представлен пример расчета дпиннопериодных статических поправок, компенсирующих аномалии зоны ММП по особо искаженной мерзлотными явлениями площади в Западной Сибири.

Учет скоростных неоднородностей в верхней части разреза основывается на анализе искажений скоростей ОГТ и линий То по ниже залегаюпим опорным горизонтам.

После расчета горизонтальньх спектров скоростей ОГТ по выбранным базовым горизонтам, начиная с самого мелко залегающего горизонта, наиболее точно характеризуюпего аномалии ВЧР по данной площади (горизонт I), были построены скомпенсированные структурные карты, согласованные со скважинными данными. Далее по методу замешения слоя была получена карта компензирующих статических поправок, изменяющихся в большом диапазоне и кардинально меняющих структурный план данной площади в соответствии с поведением структурной поверхности, подтвержденной скважинами (рис.1-2).

В результате применения методики повысилась кондиционность результатов детальной обработки и интерпретации данных за счет устранения факторов аномалий времен и амплитуд в сейсмоданных, связанных с неоднородной ВЧР, а также сократились погрешности результатов структурного картирования по данным 3Д-сейсморазведки в условиях Западной Сибири за счет учета скоростной модели ВЧР.

Глобальное уточнение структурното плана по данной площади (рис. 2) позволило на дальнейших этапах интерпретации проследить контур газоносности по картам амплитуд сейсмической записи по отражающему горизонту $G$ и сопоставить со структурной поверхностью горизонта $G$, которая впоследствии подтвердилось бурением.

Корректность введения поправок по сечениям суммарного куба оценивается по сходству горизонтов на разрезах разюьх удалений, повышению стабильности формы сигналов отражений, по повышению качества суммирования, повышению когерентности и разрешенности записи. С вводом поправок спектры скоростей становятся более динамически выраженными, поле скоростей суммирования в результате коррекции длиннопериодных составляющих выравнивается и становится более связанным с поведением горизонтов и с возможными латеральныги изменениями скорости в отдельных слоях (рис.3)

Таким образом, исходя из вышеуказанных критериев и полученных результатов, можно сделать вывод, что применение данной методики позволило достаточно точно восстановить истинную геометрию отражающих границ на этой площади, улучшить прослеживаемость целевых горизонтов, повысить когерентность данных и разрешенность записи за счет устранения негиперболичности годографа.

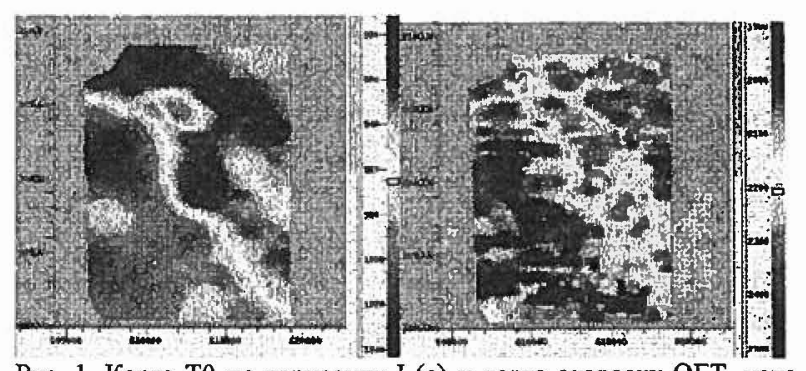

Рис. 1. Карта Т0 по горизонту I (a) и карта скорости ОГТ, искаженной аномалиями ММП по горнзонту I (б)

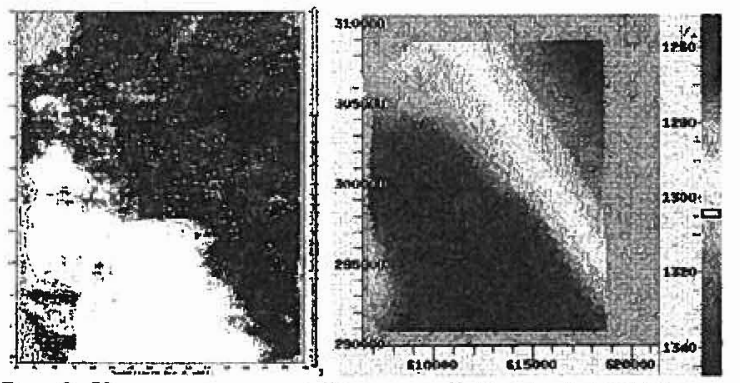

Рис. 2. Карта амплитуд сейсмической записи с очерченњым контуром газоносности по горизонту G (а); Скомтенсированная структурная карта по горизонту $G(6)$.

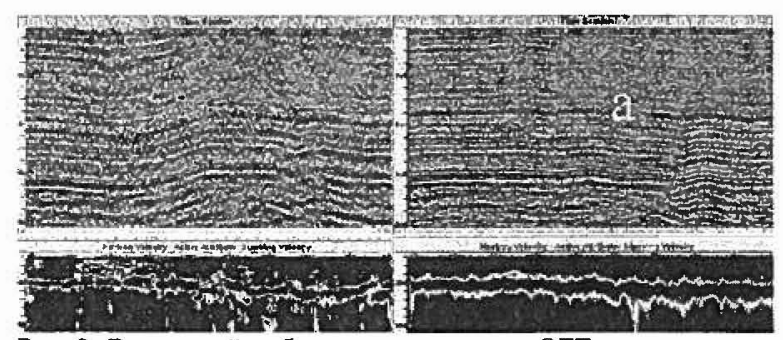

Рис. 3. Временной куб и спектр скорости ОГТ по отражающему горизонту I до (а) и пос.те учета аномалий ММП (б). 